\title{
Ten-year review of survival and management of malignant glioma in Hong Kong
}

\author{
Danny TM Chan *, Sonia YP Hsieh, Claire KY Lau, Michael KM Kam, Herbert HF Loong, WK Tsang, \\ Darren MC Poon, WS Poon
}

\section{A B S T R A C T}

Introduction: Surgical resection used to be the mainstay of treatment for glioma. In the last decade, however, opinion has changed about the goal of surgical resection in treating glioma. Ample evidence shows that maximum safe resection in glioblastoma improves survival. Neurosurgeons have therefore revised their objective of surgery from diagnostic biopsy or limited debulking to maximum safe resection. Given these changes in the management of glioma, we compared the survival of local Chinese patients with glioblastoma multiforme over a period of 10 years.

Methods: We retrospectively reviewed the data of the brain tumour registry of the CUHK Otto Wong Brain Tumour Centre in Hong Kong. Data of patients with glioblastoma multiforme were reviewed for two periods, during 1 January 2003 to 31 December 2005 and 1 January 2010 to 31 December 2012. Overall survival during these two periods of time was assessed by Kaplan-Meier survival estimates. Risk factors including age, type and extent of resection, use of chemotherapy, and methylation status of $\mathrm{O}^{6}$-methylguanine-DNA methyltransferase were also assessed.

Results: There were 26 patients with glioblastoma multiforme with a mean age of 52.2 years during 2003 to 2005, and 42 patients with a mean age of 55.1 years during 2010 to 2012 . The mean overall survival during these two periods was 7.4 months and 12.7

This article was published on 2 Dec 2016 at www.hkmj.org. months, respectively $(\mathrm{P}<0.001)$. The proportion

similar: $69.2 \%$ in 2003 to 2005 versus $78.6 \%$ in 2010 to $2012(\mathrm{P}=0.404)$. There was a higher proportion of patients in whom surgery achieved total removal in 2010 to 2012 than in 2003 to 2005 (35.7\% and 7.7\%, respectively; $\mathrm{P}=0.015)$. During 2010 to 2012 , patients who were given concomitant chemoradiotherapy showed definitively longer survival than those who were not ( 17.9 months vs 4.5 months; $\mathrm{P}=0.001)$. The proportion of patients who survived 2 years after surgery increased from $11.5 \%$ in 2003 to 2005 to $21.4 \%$ in 2010 to 2012.

Conclusions: Hong Kong has made substantial improvements in the management of glioblastoma multiforme over the last decade with corresponding improved survival outcomes. The combination of an aggressive surgical strategy and concomitant chemoradiotherapy are probably the driving force for the improvement.

\section{Hong Kong Med J 2017;23:134-9}

DOI: $10.12809 / \mathrm{hkmj} 164879$

DTM Chan *, FRCS, FHKAM (Surgery)

SYP Hsieh, MB, BS, MSC

CKY Lau, MSc

MKM Kam, FRCR, FHKAM (Radiology)

HHF Loong, MB, BS, MRCP (UK)

WK Tsang, FRCR, FHKAM (Radiology)

DMC Poon, FRCR, FHKAM (Radiology)

WS Poon, FRCS, FHKAM (Surgery)

CUHK Otto Wong Brain Tumour Centre, 1/F, Sir Yue-kong Pao Centre for Cancer, Prince of Wales Hospital, Shatin, Hong Kong

* Corresponding author: tmdanny@surgery.cuhk.edu.hk

New knowledge added by this study

- Maximum safe resection of glioblastoma multiforme (GBM) is feasible and has improved survival of patients over the last decade.

- Concomitant chemoradiotherapy has been shown to improve overall survival of patients with GBM. Implications for clinical practice or policy

- A combined multidisciplinary approach with surgery, radiotherapy, and chemotherapy should be adopted for treatment of GBM.

\section{Introduction}

Glioblastoma multiforme (GBM) is a malignant primary brain tumour with an incidence of 1 to 2 per 100000 population in Hong Kong. ${ }^{1}$ The survival of patients with GBM remains dismal, mainly due to its inevitable progression and recurrence. Little progress was made until the last decade. The establishment of concomitant chemoradiotherapy (CCRT) with temozolomide (TMZ) and the discovery of $\mathrm{O}^{6}$-methylguanine-DNA methyltransferase (MGMT) promoter methylation in association with significantly better outcome were the two major and inspiring breakthroughs. ${ }^{2,3}$ Before these developments, the treatment for GBM was 
homogeneous but desperate, and comprised surgery and irradiation only.

In 2001, TMZ was first used in the treatment of recurrent high-grade glioma in Hong Kong. Its favourable anti-tumour activity and acceptable safety profile were proven in a local study. ${ }^{4}$ In 2005 , TMZ was the first chemotherapy to show objective survival benefit as a primary treatment when used together with radiotherapy as part of CCRT in GBM. ${ }^{2}$ Since then, CCRT for GBM has become the norm in Hong Kong.

In the last decade, opinion has changed about the goal of surgical resection in treating glioma. Ample evidence has shown that maximum safe resection in GBM improves survival. Neurosurgeons have therefore revised their objective of surgery from a diagnostic biopsy or limited debulking to a maximum safe resection. Knowing the infiltrative nature of the tumour, surgeons have a demanding job of balancing maximum resection and safe surgery. Awake craniotomy and mapping technique are two essential surgical techniques that enable safe resection. ${ }^{5}$ The goal of maximum resection can be achieved with a fluorescence-guided surgery with 5-aminolevulinic acid (5-ALA). ${ }^{6}$

Given these changes to the management of GBM, we therefore analysed the changes in overall survival of GBM over the past 10 years in Hong Kong.

\section{Methods}

Data were retrieved from the Chinese University of Hong Kong Otto Wong Brain Tumour Centre brain tumour registry. The registry has been collecting data from all histology-proven glioma patients in the institute since January 2003. Patients aged 18 years or above with histologically proven glioma diagnosed in the institute were included in the registry. Patients with histologically confirmed World Health Organization grade IV GBM during January 2003 to December 2005 and January 2010 to December 2012 were recruited and grouped. Patients treated between 2006 and 2009 were excluded because the surgical policy was evolving and the availability of chemotherapy was variable during the period. Therefore this would be a heterogeneous group of patients with various treatments due to availability or affordability. Patients with an unstable neurological condition or who were considered a poor medical risk after surgery resulting in Karnofsky Performance Scale score of below 70 were excluded, as were those who received initial chemotherapeutics other than TMZ, ie procarbazine, lomustine, vincristine, or bevacizumab. Data on type of surgery, extent of resection, tumour histology, irradiation and chemotherapy parameters were collected as well as information about patient's age and gender. The registry defined the death date according to the

\section{回顧香港十年期間惡性膠質瘤患者的存活期與 治療}

陳達明、謝宜蘋、劉嘉怡、甘冠明、龍浩鋒、曾偉光、 潘明駿、潘偉生

引言: 手術切除一向是治療膠質瘤的主要治療方法, 可是過去十年醫 學界對這種手術切除的目的有所改變。有大量證據顯示在安全前提下 進行最大程度的切除可改善膠質母細胞瘤患者的存活期。因此腦外科 醫生已把手術目標從診斷活檢或有限減壓改為最大安全切除術。有見 於治療方法的改變, 本研究比較這十年期間本地多形性神經膠質母細 胞瘤 (GBM) 華籍患者的存活率。

方法：我們回顧了香港中文大學王連大腦腫瘤中心 2003 年 1 月 1 日至 2005 年 12 月 31 日以及 2010 年 1 月 1 日至 2012 年 12 月 31 日兩段期間的數 據。以Kaplan-Meier存活曲線法研究兩段期間病人的總存活期, 並評 估GBM的危險因素, 包括年齡、切除腫瘤的類型和程度、化療的使 用, 以及DNA損傷修復基因 $\mathrm{O}^{6}$-甲基鳥嘌呤 DNA 甲基轉移酶的甲基化 狀態。

結果： 2003 至 2005 年期間共有 26 例 GBM, 患者平均年齡 52.2 歲；2010至2012年則有 42 例 GBM, 患者平均年齡55.1歲。兩段期 間的患者總存活期分別為 7.4個月和 12.7 個月 $(\mathrm{P}<0.001)$; 接受手 術切除的患者比例相若, 分別為69.2\%和78.6\%（P=0.404）。2010 至2012年接受手術完全切除的患者比例 $(35.7 \%)$ 比2003至2005年 （7.7\%）為高（P=0.015）。2010至2012年間同時接受放射化療的患 者比無接受放射化療的患者存活時間明顯較長（17.9個月比4.5個月; $\mathrm{P}=0.001$ ）。存活兩年的患者比例從 2003 至2005年的 $11.5 \%$ 增至 2010 至 2012 年的 $21.4 \%$ 。

結論：過去十年香港在治療GBM方面取得重大進展, 也改善了病人存 活期。積極手術干預及放射化療的組合可能是改善的原因。

electronic patient record in the Hospital Authority Clinical Management System. For patients who defaulted from clinical follow-up, telephone followup ascertained death date. The study end date was 30 June 2015.

During 2003 to 2005, all patients were treated with surgical resection and adjuvant radiotherapy; TMZ was only used in patients with recurrent disease. Ability to pay for chemotherapy was the key determinant of its application and utility. In our hospital, TMZ was prescribed at a dose of $200 \mathrm{mg} / \mathrm{m}^{2}$ once per day for 5 days in a 28-day cycle.

With regard to the contouring methodology of irradiation, either European Organisation for Research and Treatment of Cancer or Radiation Therapy Oncology Group protocol was chosen according to the serial assessment of both pre- and post-operative magnetic resonance imaging (MRI) scans. A total dose of 60 Gy irradiation was delivered to the tumour bed and its adjacent tissue in 30 fractions, with 2 Gy each.

Since 2009, neuroradiologists have been responsible for assessing the extent of resection by MRI on postoperative day 1 . Total resection was defined as no remaining contrast enhancement on 
TABLE. Demographics, management, and survival of patients

\begin{tabular}{|c|c|c|c|c|}
\hline & \multicolumn{2}{|c|}{$2003-2005(n=26)$} & \multicolumn{2}{|c|}{$2010-2012(n=42)$} \\
\hline & No. (\%) of patients* & Median OS (months) & No. (\%) of patients* & Median OS (months) \\
\hline Mean age (years) & 52.2 & 7.4 & 55.1 & 12.7 \\
\hline Gender (M:F) & $16: 10$ & - & $28: 14$ & \\
\hline \multicolumn{5}{|l|}{ Type of surgery } \\
\hline Biopsy & $8(30.8)$ & $7.2 \S$ & $9(21.4)$ & $4.5 \S$ \\
\hline Resection & $18(69.2) \dagger$ & 7.4 & $33(78.6) \dagger$ & 15.2 \\
\hline Debulking & $16(61.5)$ & 7.2 & $18(42.9)$ & 13.0 \\
\hline Total resection & $2(7.7) \ddagger$ & - & $15(35.7) \ddagger$ & 16.0 \\
\hline \multicolumn{5}{|l|}{ MGMT } \\
\hline Methylation & N/A & - & $19(45.2)$ & 28.4 \\
\hline Unmethylation & N/A & - & $14(33.3)$ & 6.3 \\
\hline \multicolumn{5}{|c|}{ Post-surgical treatment } \\
\hline Surgery + CCRT & 0 & N/A & $23(54.8)$ & 17.9 \\
\hline Surgery + RT & $26(100)$ & $7.4 \|$ & $19(45.2)$ & $4.5 \|$ \\
\hline 2-Year survival & $3(11.5)$ & - & 9 (21.4) & - \\
\hline
\end{tabular}

Abbreviations: $\mathrm{CCRT}=$ concomitant chemoradiotherapy; $\mathrm{MGMT}=\mathrm{O}^{6}$-methylguanine-DNA methyltransferase; $\mathrm{N} / \mathrm{A}=$ not applicable; OS = overall survival; $\mathrm{RT}$ = radiotherapy

* Unless otherwise stated

$+\mathrm{P}=0.404$, Chi squared test

‡P=0.015, Chi squared test

$\S P=0.232$, log-rank test

\| $P=0.431$, log-rank test

MRI T1-weighted and subtraction scans of T1 plain with $\mathrm{T} 1$ plus contrast. For patients in whom the

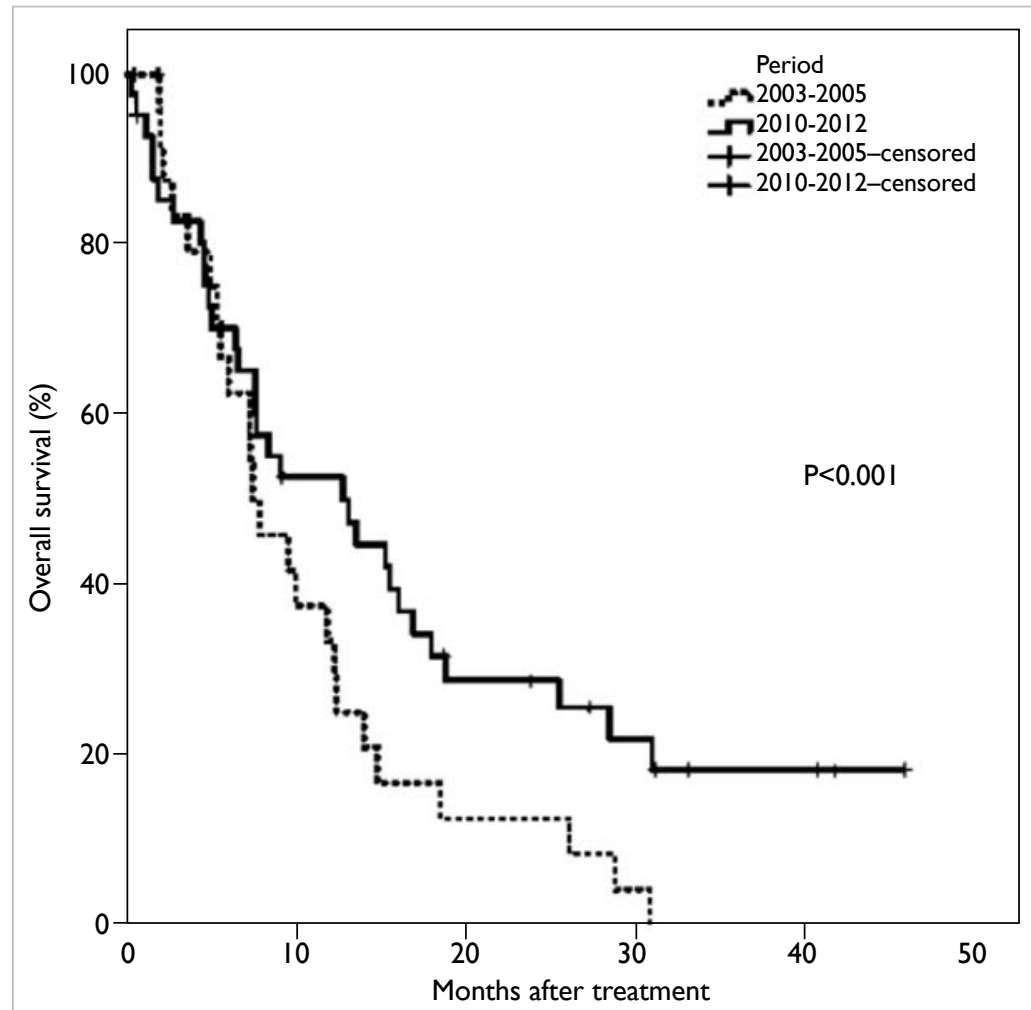

FIG I. Kaplan-Meier curves for overall survival of patients during the two periods 2003-2005 ( $n=26): 7.4$ months; $2010-2012$ ( $n=42)$ : I 2.7 months enhancing lesion was still noticeable, the resection was categorised as debulking.

In the 2010-2012 cohorts, TMZ was recommended to all patients. The dosage was 75 $\mathrm{mg} / \mathrm{m}^{2} /$ day concomitant with radiotherapy, then $150-200 \mathrm{mg} / \mathrm{m}^{2} /$ day on the first 5 days every 4 weeks for 6 cycles, in accordance with the regimen described by Stupp et al. ${ }^{2}$ Methylation status of the MGMT was detected using methylation-specific polymerase chain reaction at our institution. The method has been explained in detail in one of our earlier studies. ${ }^{7}$ Survival was calculated from the date of surgery for brain tumour to death. KaplanMeier survival curves were used to compare different groups of biopsy versus surgical resection and chemoradiotherapy versus radiotherapy alone.

This audit review was done in accordance with the principles outlined in the Declaration of Helsinki.

\section{Results}

Demographics, management, and survival of patients are shown in the Table.

During the period 1 January 2003 to 31 December 2005, 26 patients with a mean age of 52.2 years were eligible for study. Two patients below the age of 18 years were excluded from the registry. The median overall survival for this cohort was 7.4 months (Fig 1). Eight (30.7\%) patients underwent 
biopsy only, with a non-inferior median overall survival compared with the remaining 18 patients who underwent resection (7.2 months vs 7.4 months, $\mathrm{P}=0.988$, log-rank test; Fig 2). Total removal could be achieved in only two patients, with overall survival of 14.7 and 28.8 months, respectively. For the remaining 16 patients who underwent debulking surgery, the median overall survival was 7.2 months.

During the period 1 January 2010 to 31 December 2012, 42 patients with a mean age of 55.1 years were identified. One patient was excluded because he declined CCRT after surgery and opted for alternative medicine. The median overall survival was markedly prolonged to 12.7 months $(\mathrm{P}<0.001$, log-rank test; Fig 1$)$. The proportion of patients who had biopsy $(9 / 42,21.4 \%)$ during 2010 to 2012 remained similar to 10 years ago $(8 / 26$, $30.8 \%)$. Patients with resection performed was not significantly different between the two periods ( $P=0.404$, Chi squared test). Overall survival of the surgical resection group was distinctly longer than that for the biopsy group (15.2 months and 4.5 months, respectively; $\mathrm{P}=0.026$, log-rank test; Fig 3 ). A higher proportion of patients achieved total surgical removal in 2010-2012 than in 2003-2005, being $35.7 \%(15 / 42)$ and $7.7 \%(2 / 26)$, respectively $(\mathrm{P}=0.015$, Chi squared test). The difference between debulking and total resection remained undefined in the 2010-2012 arm (13.0 months vs 16.0 months; $\mathrm{P}=0.966$, log-rank test) by the time of analysis.

Of the 42 patients with GBM during 20102012, CCRT was initiated in 23, accompanied by a meaningful longer median survival of 17.9 months compared with only 4.5 months for those given radiotherapy only ( $\mathrm{P}=0.001$, log-rank test; Fig 4$)$. Data for MGMT were available in 33 patients. The overall survival of 19 patients with methylated MGMT promoter was longer than that of 14 patients with unmethylated MGMT promoter, being 28.4 months and 6.3 months, respectively $(\mathrm{P}<0.001$, logrank test).

Improvement in 2-year survival was also evident, from $11.5 \%$ in the earlier cohort, to $21.4 \%$ in the later one.

\section{Discussion}

Glioma has attracted international research interest over the last 20 years in both clinical and laboratory setting. The determination to fight the disease yielded with proven survival benefit of TMZ in recurrent high-grade glioma in $2000 .^{8}$ A 6-month event-free survival of $21 \%$ in TMZ compared favourably with 9\% for procarbazine. ${ }^{8}$ The full effect of TMZ was reported in a randomised trial as primary treatment for GBM in 2005. ${ }^{2}$ The regimen included two phases of TMZ, starting with a concomitant phase of daily low-dose TMZ during the course of radiotherapy, followed by the adjuvant phase of a high-dose TMZ

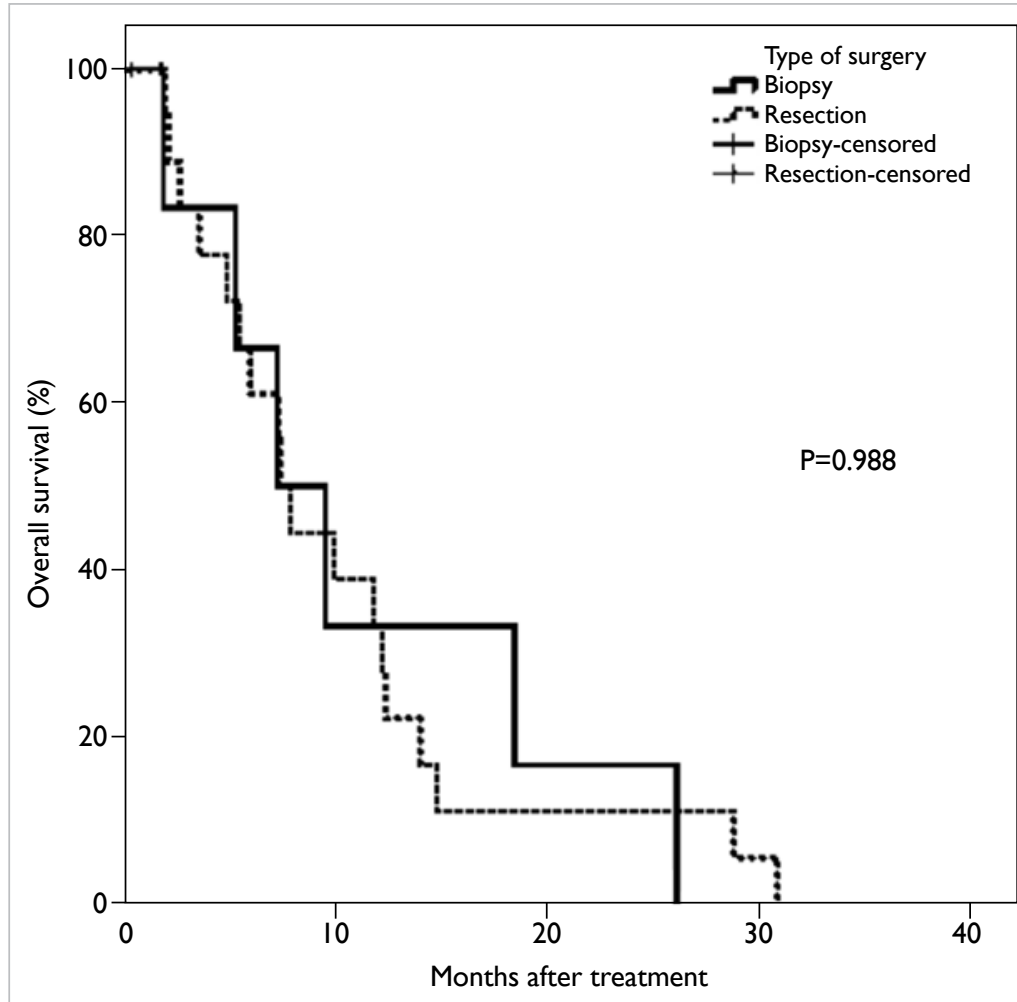

FIG 2. Kaplan-Meier curves for overall survival of the biopsy group and surgical resection group during 2003 to 2005

Biopsy ( $n=8)$ : 7.2 months; resection $(n=\mid 8)$ : 7.4 months

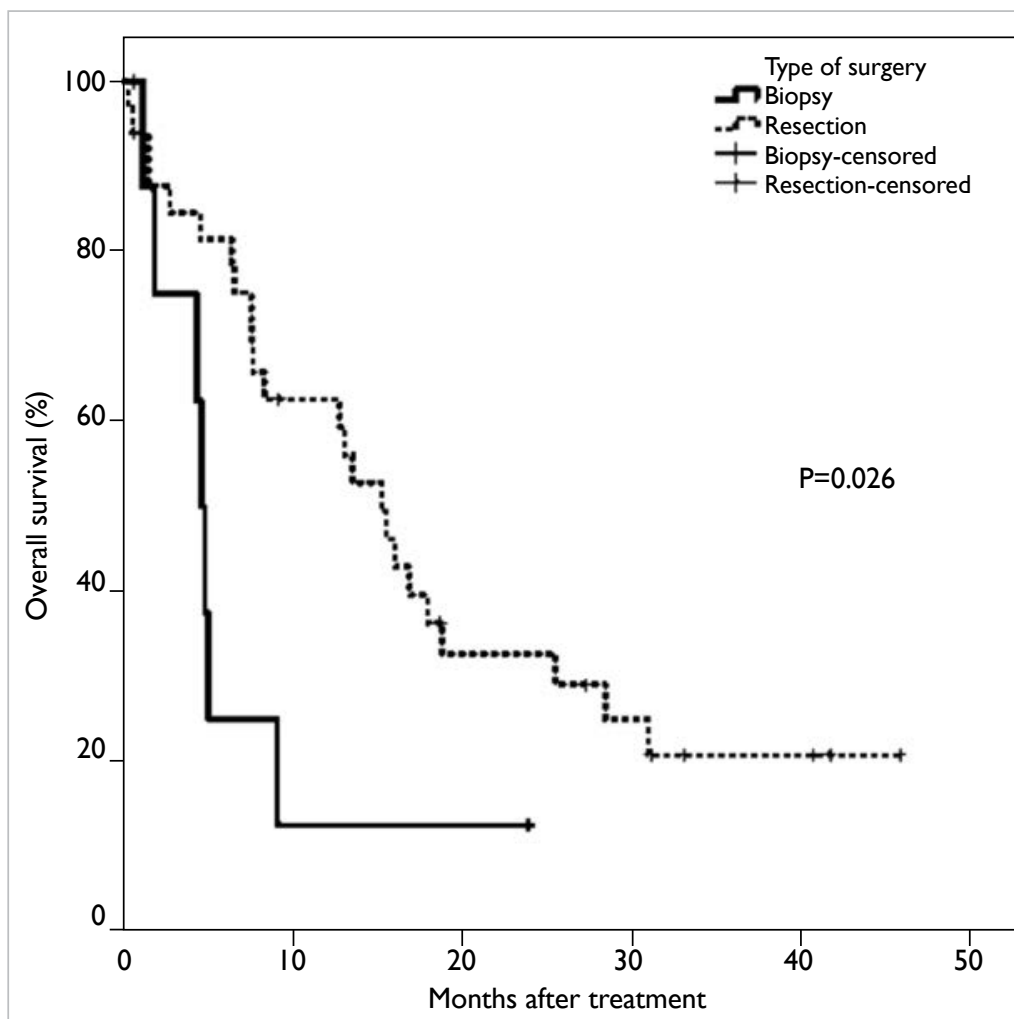

FIG 3. Kaplan-Meier curves for overall survival of the biopsy group and surgical resection group during 2010 to 2012

Biopsy ( $n=9)$ : 4.5 months; resection $(n=33)$ : 15.2 months 


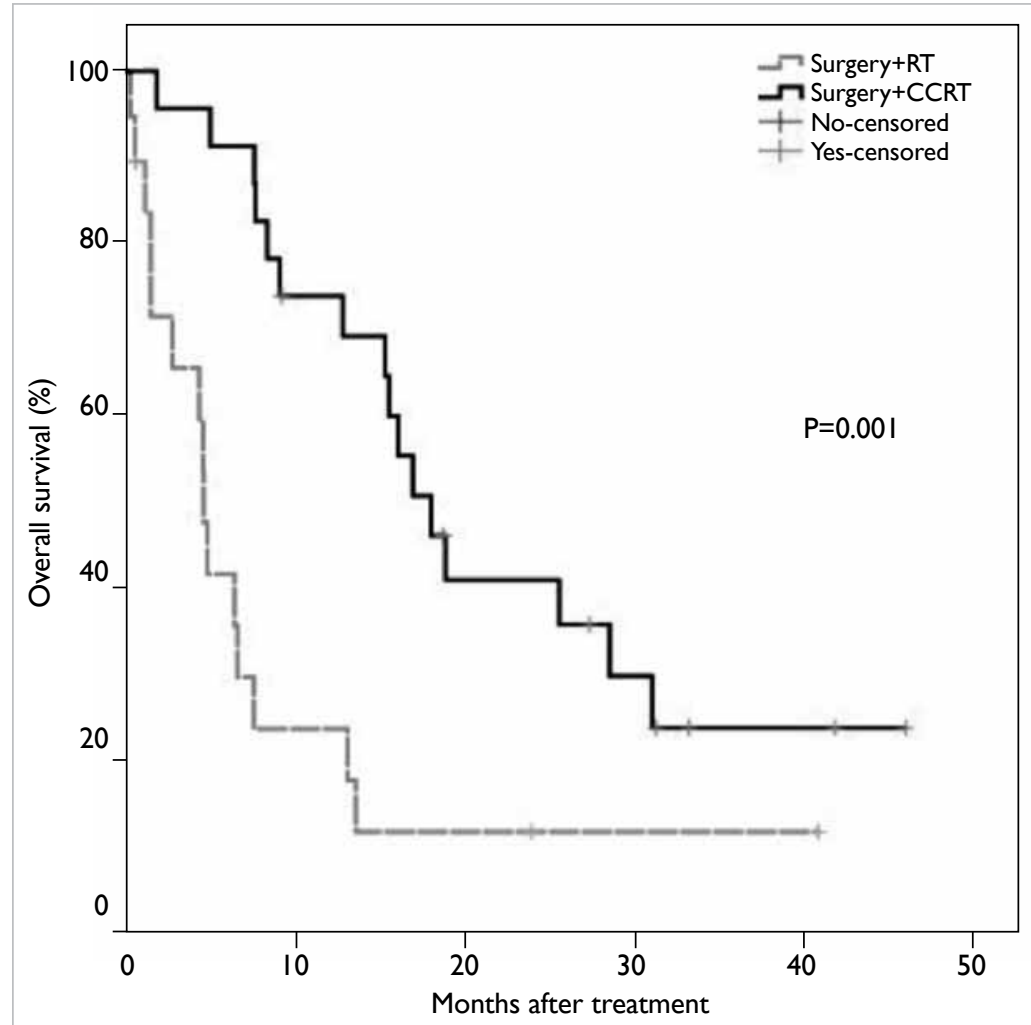

FIG 4. Kaplan-Meier curves for overall survival of the surgery plus concomitant chemoradiotherapy (CCRT) group and surgery plus radiotherapy (RT) group during 2010 to 2012

Surgery + CCRT ( $n=23): 17.9$ months versus surgery + RT $(n=19): 4.5$ months for 5 days during each 28-day cycle for 6 cycles. $^{2}$ The results of the study benchmarked a standard for chemotherapy in the treatment of GBM. The median survival of 14.6 months in the CCRT arm compared favourably with the 12.1 months of the control radiotherapy-alone arm. ${ }^{2}$

In Hong Kong, TMZ was first introduced in 2001. Its safety and effect had been tested and reported in a small series of recurrent high-grade glioma. ${ }^{4}$ The use of CCRT in Hong Kong was also reported with favourable results. ${ }^{9}$ The overall survival was much improved in these 10 years from 7.4 months in 2003-2005 to 12.7 months in 20102012. Among the cohorts in 2010-2012, however, only $54.8 \%(23 / 42)$ received CCRT. This can be attributed to the fact that in 2010, TMZ, whilst already incorporated into the Hospital Authority Drug Formulary, was listed as a self-financed item only. The financial burden on patients was the major cause of low usage during the time.

In 2011, TMZ was granted conditional funding through the Samaritan Fund scheme. Approval of funding was based on the financial situation of the patient and the tumour's MGMT methylation status, with approval only granted to patients with tumours with MGMT methylation. This may have been a cost-effectiveness consideration because the largest survival benefit would be in MGMT-methylated GBM. Local data showed that only $43 \%$ of local GBM were methylated in MGMT status, ${ }^{9}$ thus essentially limiting the possibility of funding for less than half of the patients with GBM. Thus, within the 20102012 cohort, only patients diagnosed from 2011 onwards with tumours of methylated MGMT status (accounting for roughly a further half of the patient population) would have benefited from the scheme. This may account for the relatively low number of patients treated with CCRT. Then the policy of restricting funding based on MGMT status was readdressed and such criterion was removed in 2013. Currently, support of Samaritan Fund for TMZ is available for eligible patients with GBM based on their financial situation, and regardless of their tumour MGMT status.

The treatment of CCRT had made an impact not only on clinical outcomes, but also on the working dynamics between different professional disciplines involved in the management of patients with GBM. The need for timely arrangement and administration of radiotherapy and chemotherapy within a short postoperative window has encouraged a multidisciplinary team approach. This continues to be the current treatment delivery model for patients with GBM in many hospitals in Hong Kong. Better clinical outcomes encouraged professional enthusiasm. In this atmosphere, a local group of clinicians got together and founded the Hong Kong Neuro-Oncology Society in 2011.

The reasons for longer survival of GBM in recent years are likely to be multifactorial. The extent of surgical resection has been intensely studied over the last two decades. Nonetheless, since a prospective randomised surgical study would be unethical, evidence to support maximum safe resection must be gleaned retrospectively. Despite this, neurosurgical professionals were convinced that surgical resection was the first and major treatment for GBM. Surgical conservatism was abandoned and the demand for maximum safe resection was set out by neurosurgeons. This change was reflected in the decrease in surgical biopsy rate from $30.8 \%$ in $2003-2005$ to $21.4 \%$ in $2010-2012$. The ability of total surgical removal of the contrast-enhancing tumour was also increased from $7.7 \%$ in 20032005 to $35.7 \%$ in 2010-2012. Local neurosurgeons have been equipped with two surgical techniques to achieve maximum safe resection in the last 10 years - the technique of cortical mapping and awake surgery was brought to all local neurosurgeons in two workshops of commissioned training organised by the Hospital Authority in 2003 and 2010. This technique allows safer resection of the tumour at 
or near the eloquent area of the brain. A tumour fluorescent technique (5-ALA) was introduced in 2009 that facilitated detection of residual tumour for maximum resection. In 2003-2005, the survival of the surgical resection group and biopsy group was similar but in 2010-2012, those in the surgical resection group survived longer. The difference was probably due to both aggressive surgical resection and CCRT in the latter group.

The major limitation of this study was the presence of potential confounding factors during the 10-year study period. Such factors included incomplete data of MGMT methylation status and extent of resection in the 2003-2005 group. There was no MGMT methylation testing or day-1 MRI scan after resection in 2003-2005. The interval between surgery and commencement of radiotherapy has been controlled to within 4 weeks since 2009 but this was not the case in 2003-2005. All these confounding factors made valid comparison of the effect of surgical resection or chemotherapy during these two time periods difficult. Moreover, the registry included only surgical patients who had undergone biopsy or resection, and excluded a small group of patients, who were usually elderly (age $>70$ years) or with poor co-morbidities, who may have received radiotherapy or chemotherapy alone.

\section{Conclusions}

Hong Kong has made substantial improvements in the management of GBM with improved survival over the last decade. The combination of aggressive surgical strategy and CCRT are probably the driving force for the improvement.

\section{Declaration}

None of the authors has disclosed any conflicts of interest.

\section{References}

1. Pu JK, Ng GK, Leung GK, Wong CK. One-year review of the incidence of brain tumours in Hong Kong Chinese patients as part of the Hong Kong Brain and Spinal Tumours Registry. Surg Pract 2012;16:133-6.

2. Stupp R, Mason WP, van den Bent MJ, et al. Radiotherapy plus concomitant and adjuvant temozolomide for glioblastoma. N Engl J Med 2005;352:987-96.

3. Hegi ME, Diserens AC, Gorlia T, et al. MGMT gene silencing and benefit from temozolomide in glioblastoma. N Engl J Med 2005;352:997-1003.

4. Chan DT, Poon WS, Chan YL, Ng HK. Temozolomide in the treatment of recurrent malignant glioma in Chinese patients. Hong Kong Med J 2005;11:452-6.

5. Chan DT, Kan PK, Lam JM, et al. Cerebral motor cortical mapping: awake procedure is preferable to general anaesthesia. Surg Pract 2010;14:12-8.

6. Stummer W, Pichlmeier U, Meinel T, et al. Fluorescenceguided surgery with 5-aminolevulinic acid for resection of malignant glioma: a randomised controlled multicentre phase III trial. Lancet Oncol 2006;7:392-401.

7. Dong SM, Pang JC, Poon WS, et al. Concurrent hypermethylation of multiple genes is associated with grade of oligodendroglial tumors. J Neuropathol Exp Neurol 2001;60:808-16.

8. Yung WK, Albright RE, Olson J, et al. A phase II study of temozolomide vs. procarbazine in patients with glioblastoma multiforme at first relapse. Br J Cancer 2000;83:588-93.

9. Chan DT, Kam MK, Ma BB, et al. Association of molecular marker $\mathrm{O}^{6}$ Methylguanine DNA methyltransferase and concomitant chemoradiotherapy with survival in Southern Chinese glioblastoma patients. Hong Kong Med J 2011;17:184-8. 